\title{
Mechanical Ventilation in Patients with End-Stage Idiopathic Pulmonary Fibrosis
}

\author{
Corrado Mollica ${ }^{a}$ Gregorino Paone $^{\mathrm{e}, \mathrm{f}}$ Vittoria Conti ${ }^{\mathrm{e}}$ Daniela Ceccarelli ${ }^{\mathrm{e}}$ \\ Giovanni Schmid $^{f}$ Paolo Mattia $^{b}$ Nicola Perrone ${ }^{c}$ Angelo Petroianni $^{\mathrm{e}}$ \\ Alfredo Sebastiani $^{a}$ Luca Cecchini $^{a}$ Remo Orsetti ${ }^{d}$ Claudio Terzano

\begin{abstract}
${ }^{a}$ Respiratory Intermediate Intensive Care Unit, ${ }^{b}$ Radiological Unit, ${ }^{c}$ Unit of Pulmonary Physiopathology, and
dIntensive Care Unit, S. Camillo-Forlanini Hospital, e Department of Cardiovascular and Respiratory Sciences,
\end{abstract} \\ University La Sapienza, and ${ }^{\mathrm{f} T}$ The Don Gnocchi Foundation S. Maria Della Pace, Rome, Italy
}

\section{Key Words}

Acute respiratory failure $\cdot$ Idiopathic pulmonary fibrosis • Invasive mechanical ventilation $\cdot$ Non-invasive mechanical ventilation

\begin{abstract}
Background: Acute respiratory failure (ARF) occurring during idiopathic pulmonary fibrosis (IPF) is associated with a poor prognosis. In this subset of individuals, mechanical ventilation (MV) may be required. Objectives: We analysed the characteristics of a group of IPF patients undergoing MV for ARF in order to give some indications on the supposed prognosis. Methods: Hospital records of 34 consecutive patients with IPF, who underwent MV for ARF, were retrospectively examined. Demographic data, time from diagnosis, gas exchange, Acute Physiology and Chronic Health Evaluation (APACHE) II score, ARF causes and MV failure were recorded. Results: Fifteen subjects (group A) underwent invasive MV and 19 patients (group B) non-invasive ventilation (NIV). The 2 groups were different for disease severity (APACHE II score $24.2 \pm 6$ vs. $19.5 \pm 5.9 ; p=0.01$ ). Both ventilatory strategies temporarily increased $\mathrm{PaO}_{2} / \mathrm{FiO}_{2}$ as compared with spontaneous breathing (group A: $148.5 \pm 52$ vs. $99 \pm 39, p=0.0004 ;$ group B: $134 \pm 36$ vs. $89 \pm 26, p=$ $0.0004)$. NIV reduced the respiratory rate ( $26 \pm 7$ vs. $36 \pm 9$
\end{abstract}

with spontaneous breathing; $p=0.002)$. Duration of MV correlated with the time of evolution of IPF $(r=0.45 ; p=0.018)$. The in-hospital mortality rate was $85 \%$ (100\% for invasive MV, $74 \%$ for NIV). Four of the 5 survivors died within 6 months from hospital discharge (range 2-6 months). Conclusions: $M V$ does not appear to have a significant impact on the survival of patients with end-stage IPF. NIV may be useful for compassionate use, providing relief from dyspnoea and avoiding aggressive approaches.

Copyright $\odot 2009$ S. Karger AG, Basel

\section{Introduction}

Idiopathic pulmonary fibrosis (IPF) is a progressive inflammatory interstitial lung disease characterized by relative unresponsiveness to therapy and a poor prognosis with a median survival after diagnosis ranging from 3 to 5 years [1]. Although the clinical course is usually slowly progressive, some patients experience a rapid decline, and acute respiratory failure (ARF) can develop during the course of the disease. In this subset of subjects, mechanical ventilation (MV) may be required, although

\section{C.M. and G.P. contributed equally to this work.}

\section{KARGER}

Fax +4161306 1234 E-Mail karger@karger.ch www.karger.com (c) 2009 S. Karger AG, Basel

0025-7931/10/0793-0209\$26.00/0

Accessible online at:

www.karger.com/res
Claudio Terzano

Department of Cardiovascular and Respiratory Sciences

Respiratory Diseases Unit, Sapienza University of Rome

Via Casal de' Pazzi, 16, IT-00156 Rome (Italy)

Tel. +39064080 0277, Fax +39064080 0276, E-Mail cterzano@tin.it 
its effectiveness lacks consensus [2-7]. Recently, Suh and coworkers [8] reported that an early diagnostic and therapeutic approach including a 'lung protective' MV led to a favourable outcome in patients with ARF during acute interstitial pneumonia, renewing the discussion on $\mathrm{MV}$ effectiveness in IPF patients with ARF.

Poor prognosis associated with a higher risk of infections occurring during conventional MV may suggest the use of non-invasive MV (NIV).

The aim of our retrospective study was to describe the characteristics of a group of IPF patients admitted for ARF in our centre, and to give some indications on putative prognosis.

\section{Materials and Methods}

\section{Patients}

From January 2000 to January 2007, 34 consecutive patients with IPF underwent MV for ARF for at least $12 \mathrm{~h}$ [9] at S. Camillo-Forlanini Hospital, Rome. In 16 subjects, the diagnosis was obtained by lung biopsy, and in the remaining 18 by the presence of all major and at least 3 minor European Respiratory Society/ American Thoracic Society criteria for IPF diagnosis [10].

Internal review board approval for the review of medical records was obtained.

Subjects with known causes of interstitial lung disease (e.g., collagen vascular diseases, radiation/drug toxicity, neoplasm, environmental exposure, infections and post-operative observation after non-thoracic procedures) were excluded from evaluation.

ARF was defined as an acute and rapidly progressive decline in respiratory function and exacerbation of dyspnoea within a few days, associated with a deterioration of hypoxaemia with a partial pressure of arterial oxygen/fraction of inspired oxygen ratio $\left(\mathrm{PaO}_{2} / \mathrm{FiO}_{2}\right)<250[2]$.

Sepsis and shock diagnoses were based on American College of Chest Physicians/Society of Critical Care Medicine Consensus Conference (1992) criteria [11].

To assess the disease severity, we recorded the last pulmonary function tests and high-resolution computed tomography of each patient before ARF onset. An experienced study-blinded radiologist (P.M.) calculated a high-resolution computed tomography score, according to literature [2].

\section{Assessment of IPF Patients with ARF}

On the respiratory ward, demographic information, average duration of the disease from diagnosis to hospital admission, arterial blood gas, respiratory rate (RR) and heart rate were analysed. The decision to initiate NIV or to perform endotracheal intubation (ETI), in the presence of the patient's acute alteration of consciousness [12], depended on the clinical evaluation by the attending physician in the respiratory ward.

In presence of contraindications to NIV [13], individuals underwent ETI and invasive MV (iMV) was performed, unless patients had previously declared a wish not to be resuscitated.

NIV was carried out in a respiratory intermediate intensive care unit (RIICU).
During ICU/RIICU stay and upon discharge, we also recorded the reason for admission, Acute Physiology and Chronic Health Evaluation (APACHE) II score [14], length of stay, duration of MV (MV days and MV h/day), NIV failure, ETI and in-hospital mortality rate (\%).

Effectiveness of MV was calculated according to the criteria of Meduri et al. [15] slightly modified by means of the comparison between the best $\mathrm{PaO}_{2} / \mathrm{FiO}_{2}$ after a spontaneous breathing trial before starting $\mathrm{MV}$ (T0) and the best $\mathrm{PaO}_{2} / \mathrm{FiO}_{2}$ during an $\mathrm{MV}$ trial (T1). MV was considered to correct $\mathrm{PaO}_{2}$ with a difference between $\mathrm{PaO}_{2} / \mathrm{FiO}_{2}$ (T1) and $\mathrm{PaO}_{2} / \mathrm{FiO}_{2}$ (T0) $>100$, to improve $\mathrm{PaO}_{2}$ with a difference $\geq 50$, and to fail $\mathrm{PaO}_{2}$ correction with a difference $<50$.

\section{Settings}

Patients admitted to the ICU underwent ETI with cuffed tubes (internal diameters $7.5-8.5 \mathrm{~mm}$ ), after intravenous administration of midazolam (2.5-5 mg) or fentanyl $(1 \mu \mathrm{g} / \mathrm{kg})$ for sedation; all patients received propofol $(1.5-2 \mathrm{mg} / \mathrm{kg}$ of measured body weight); 7 patients also received vecuronium $(0.1 \mathrm{mg} / \mathrm{kg})$ or pancuronium $(0.05 \mathrm{mg} / \mathrm{kg})$ to obtain a better adaptation to MV. Both iMV and NIV were performed by Puritan Bennett $7200 \mathrm{~A}^{\circledR}$ ventilator (Nellcor Puritan Bennett Inc. 4280, Pleasanton, Calif., USA). Conventional ventilation (iMV) was applied in a volume-controlled mode with a mean delivered tidal volume (TV) value of 7.5 $\mathrm{ml} / \mathrm{kg}$ (range 6-9) of measured body weight. Positive end expiratory pressure (PEEP) was set in order to obtain the best oxygenation with the fewest side effects on haemodynamics [16]; arterial oxygen saturation was measured online.

NIV was performed in pressure support mode (NIPSV); a helmet (CaStar ${ }^{\circledR}$; Starmed, Mirandola, Italy) was used as an interface for all patients. Pressure support, PEEP and flow-by trigger [17] values were adjusted in order to obtain the best oxygenation and to reduce RR and were modified on the basis of blood gas data

During NIV, transcutaneous oxygen saturation was measured by a finger probe.

In both MV settings (ICU/RIICU), the blood gas balance was measured on admission, after modifying the ventilator setting, and at discharge.

The criteria for NIPSV discontinuation and shift to iMV were: onset of coma, cardiovascular instability or poor compliance to NIV device.

All along the ICU/RIICU stay, corticosteroids (methylprednisolone $0.5-1 \mathrm{~g} /$ day) and broad-spectrum antibiotic regimens were administered to all the patients.

\section{Statistical Analysis}

All statistical analyses were performed using STATISTICA 6 software (Stat Soft, Inc., Tulsa, Okla., USA).

Continuous variables were expressed as the mean \pm standard deviation. Comparisons between groups of patients were performed by the Mann-Whitney U test; the Wilcoxon test was used for intra-group analysis. Correlations between variables were calculated using the Spearman rank correlation test. The survival curve was estimated using the Kaplan-Meier method.

All $\mathrm{p}<0.05$ values were considered statistically significant. 
Table 1. Baseline characteristics of patients included in the study

\begin{tabular}{lc}
\hline Parameters & Study population $(\mathrm{n}=34)$ \\
\hline Gender, M/F & $26 / 8$ \\
Age, years & $60 \pm 11$ \\
Onset of IPF, months & $17.9 \pm 17.2$ \\
Home oxygen therapy, $\mathrm{n}$ & 12 \\
TLC, \% predicted & $59 \pm 14$ \\
$\mathrm{FVC}, \%$ predicted & $57.6 \pm 8.5$ \\
$\mathrm{FEV}_{1}, \%$ predicted & $59 \pm 12$ \\
DLCO, \% predicted & $45 \pm 13$ \\
$\mathrm{HRCT}$ score & $2.4 \pm 0.7$ \\
$\mathrm{Heart}$ rate, beats/min & $113 \pm 24$ \\
$\mathrm{RR}_{\text {breaths/min }}$ & $38 \pm 9.5$ \\
$\mathrm{Arterial} \mathrm{pH}$ & $7.41 \pm 0.09$ \\
$\mathrm{PaO}_{2} /$ FiO & \\
$\mathrm{PaCO}_{2}$, mm Hg & $101 \pm 36$ \\
$\mathrm{SaO}_{2}, \%$ & $39.3 \pm 9$ \\
$\mathrm{Glasgow}$ coma scale & $79.3 \pm 11$ \\
\hline
\end{tabular}

Data are presented as the mean \pm standard deviation from the mean. TLC = Total lung capacity; FVC = forced vital capacity; $\mathrm{FEV}_{1}=$ forced expiratory volume in $1 \mathrm{~s}$; DLCO = carbon monoxide diffusing capacity; HRCT = high-resolution computed tomography; $\mathrm{SaO}_{2}=$ arterial oxygen saturation.

\section{Results}

Baseline characteristics of patients included in the study are summarized in table 1 .

On admission, all patients were on oral corticosteroids (prednisone $20-40 \mathrm{mg} / \mathrm{day}$ ); 6 of them were on corticosteroids and azathioprine and 4 on corticosteroids and cyclophosphamide. Twelve patients were receiving longterm home oxygen therapy; none of them was on home MV. Six patients were on a waiting list for lung transplantation, 14 were potential candidates, and the remaining subjects did not fulfill the criteria for the lung transplantation program mainly due to their age.

All patients had severe functional and radiological impairment. On hospital admission, microbiological investigations for a suspected pulmonary infection (sputum culture and/or endotracheal aspiration and/or bronchoalveolar lavage, BAL) were performed upon all patients, before the introduction of an empirical antibiotic treatment.

During respiratory ward stay, although oxygen therapy in spontaneous breathing was administered at a high flow rate, no improvement in oxygenation was observed $\left(\mathrm{PaO}_{2} / \mathrm{FiO}_{2}\right.$ at admission $101 \pm 36$ vs. $\mathrm{PaO}_{2} / \mathrm{FiO}_{2}$ in spon-
Table 2. Patient characteristics at RIICU/ICU admission (T0)

\begin{tabular}{lccl}
\hline Parameters & $\begin{array}{c}\text { Group A } \\
(\mathrm{n}=15)\end{array}$ & $\begin{array}{l}\text { Group B } \\
(\mathrm{n}=19)\end{array}$ & $\begin{array}{l}\text { Signifi- } \\
\text { cance }\end{array}$ \\
\hline Age, years & $64.6 \pm 10$ & $56 \pm 11$ & $\mathrm{p}=0.03$ \\
Heart rate, beats/min & $112 \pm 25$ & $120 \pm 20$ & n.s. \\
$\mathrm{RR}$, breaths/min & $33 \pm 14$ & $36 \pm 9$ & n.s. \\
$\mathrm{Arterial} \mathrm{pH}_{\mathrm{PaO}_{2} / \mathrm{FiO}_{2}}^{7.34 \pm 0.14}$ & $7.4 \pm 0.07$ & n.s. \\
$\mathrm{PaCO}_{2}, \mathrm{~mm} \mathrm{Hg}$ & $99 \pm 39$ & $89 \pm 26$ & n.s. \\
Base excess $_{\text {Glasgow coma scale }}$ & $1.2 \pm \pm 2.5 \pm 23.4$ & $49 \pm 15.4$ & n.s. \\
APACHE II score & $24.2 \pm 6$ & $14.6 \pm 6.2$ & n.s. \\
Onset of IPF, months & $18.6 \pm 16$ & $17.8 \pm 18$ & n.s. \\
DLCO, \% predicted & $44 \pm 6$ & $48 \pm 12$ & n.s. \\
HRCT score & $2.37 \pm 0.8$ & $2.56 \pm 0.5$ & n.s \\
\end{tabular}

Data are presented as the mean \pm standard deviation from the mean. n.s. = Not significant; DLCO = carbon monoxide diffusing capacity; HRCT = high-resolution computed tomography.

taneous breathing $93.3 \pm 33 ; \mathrm{p}=$ n.s.). An increase in $\mathrm{PaCO}_{2}$ levels $(39.3 \pm 9$ vs. $53 \pm 19 \mathrm{~mm} \mathrm{Hg}$; $\mathrm{p}=0.0005)$ and a $\mathrm{pH}$ shifting towards acidosis $(7.41 \pm 0.09$ vs. 7.37 $\pm 0.11 ; \mathrm{p}=0.007)$, associated with a light deterioration of mental status (Glasgow coma scale at respiratory ward admission $14.4 \pm 1.8$ vs. Glasgow coma scale at ICU/ RIICU admission $13.4 \pm 3.3 ; \mathrm{p}=$ N.S.) were also observed. The average respiratory ward length of stay before initiating MV was $8.5 \pm 6.7$ days (range 1-20).

With the worsening of clinical conditions, 15 individuals met the criteria to undergo ETI and iMV (group A) and 19 subjects were admitted to the RIICU and received NIV (group B).

The disease severity was quite different between the 2 groups, with patients undergoing iMV showing a significantly higher APACHE II score as compared with subjects undergoing NIV $(24.2 \pm 6$ vs. $19.5 \pm 5.9 ; \mathrm{p}=0.01)$ (table 2).

\section{Patients in the ICU}

Precipitating causes of respiratory failure were known in 4 subjects (27\%) undergoing iMV (2 pneumonias, 1 heart failure and 1 cardiogenic shock). The remaining patients had no immediate precipitating factors, and the worsening of respiratory function was attributed to the progression of IPF.

The mean values of the iMV setup were collected: TV $590 \pm 128 \mathrm{ml}$ (range 350-750), PEEP $6 \pm 2 \mathrm{~cm} \mathrm{H}_{2} \mathrm{O}$ (range 2-7), $\mathrm{FiO}_{2} 84 \pm 18 \%$ (range 70-90). 
Fig. 1. Evolution of the $\mathrm{RR}, \mathrm{PaO}_{2} / \mathrm{FiO}_{2}$, $\mathrm{PaCO}_{2}$ and $\mathrm{pH}$ during $\mathrm{MV}$ settings. $\mathrm{T}_{\mathrm{adm}}=$ Time of respiratory ward admission; $\mathrm{T} 0=$ time of RIICU (black histograms, NIV) or ICU (grey histograms, iMV) admission; $\mathrm{T} 1$ = best values obtained during $\mathrm{MV}$; $\mathrm{T} 2$ = time when variables began worsening; $\mathrm{T}_{\text {disch }}=$ time of discharge/death. ${ }^{*}$ Significant differences between $\mathrm{T} 0$ and $\mathrm{T} 1$.
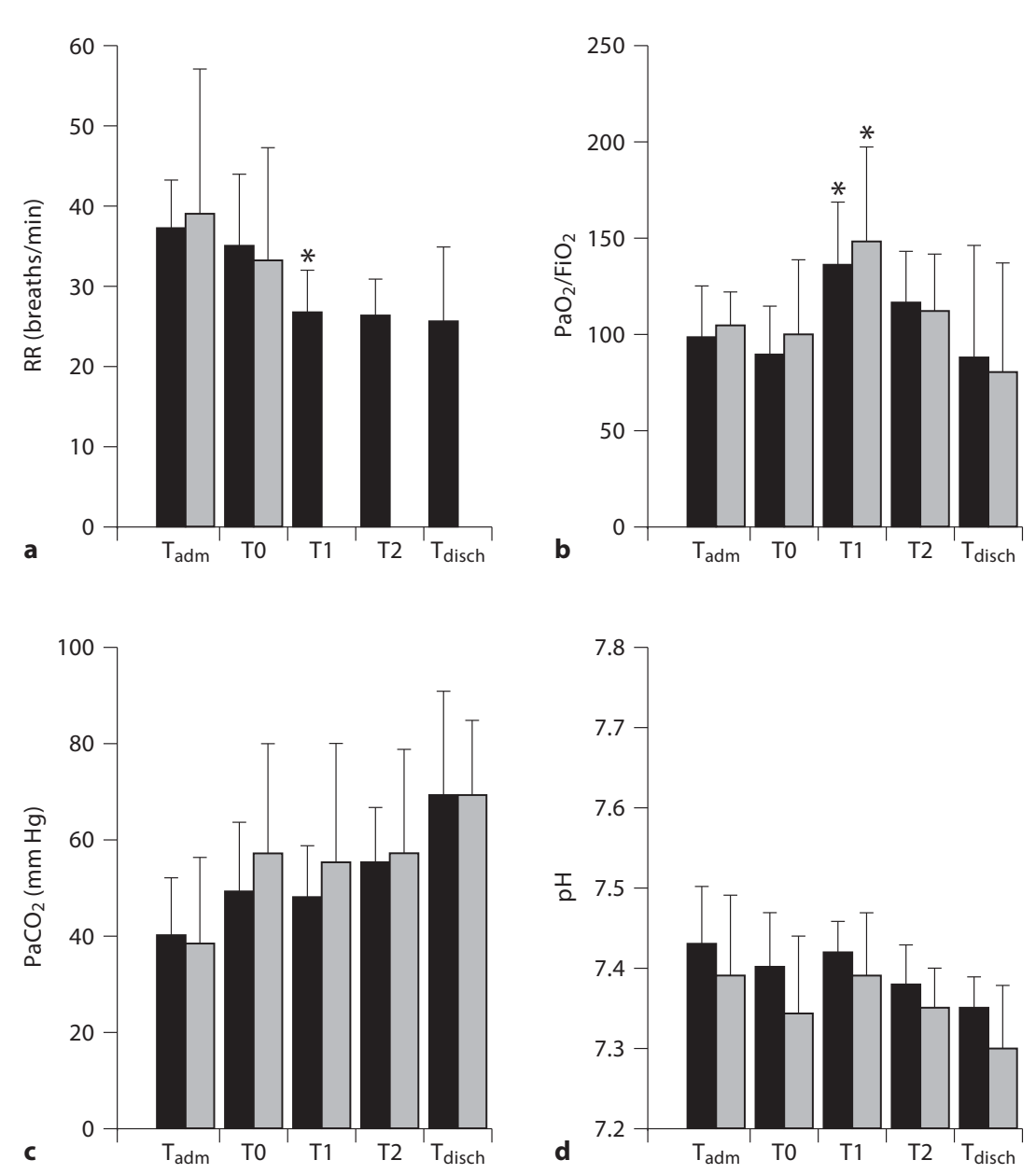

We observed a transitory significant increase in $\mathrm{PaO}_{2} /$ $\mathrm{FiO}_{2}$ values (148.5 \pm 52 vs. $\left.99 \pm 39 ; \mathrm{p}=0.0004\right)$, with no significant effects on $\mathrm{PaCO}_{2}$ and $\mathrm{pH}$ values. Conventional ventilation temporarily corrected $\mathrm{PaO}_{2} / \mathrm{FiO}_{2}$ in 4 patients, improved $\mathrm{PaO}_{2} / \mathrm{FiO}_{2}$ in 4 and failed to improve gas exchange in 7 patients.

The RR was not analysed because patients underwent $\mathrm{iMV}$ in a volume-controlled mode ( $\mathrm{RR}=12$ breaths/ $\min )$.

The median iMV duration was 7 days (range 1-16), with $20 \pm 3.5 \mathrm{~h} /$ day.

All patients died after $7.3 \pm 6.7$ days; the causes of death were septic shock in 4 patients (nosocomial pneumonia due to Enterobacterium cloacae, Staphylococcus aureus, methicillin-resistant S. aureus, Acinetobacter baumannii), cardiac arrest in 4 and heart failure with cardiogenic shock in 7 patients.

\section{Patients in the RIICU}

The causes of ARF were known in 8 patients (42\%; 3 pneumonias, 2 pneumonias with pleuritis, 1 pulmonary embolism, 1 congestive heart failure and 1 ARF after BAL).

The following initial NIPSV setting was used: pressure support $18 \pm 4 \mathrm{~cm} \mathrm{H}_{2} \mathrm{O}$ (range 15-22), PEEP $7 \pm$ $2 \mathrm{~cm} \mathrm{H}_{2} \mathrm{O}$ (range 4-10), $\mathrm{FiO}_{2} 67 \pm 24 \%$ (range 40-90).

NIV determined a temporary significant improvement in $\mathrm{PaO}_{2} / \mathrm{FiO}_{2}$ in comparison with spontaneous breathing (134 \pm 36 vs. $89 \pm 26$; $\mathrm{p}=0.0004)$ with no significant effects on $\mathrm{PaCO}_{2}$ and $\mathrm{pH}$ values.

Importantly, NIV determined a significant decrease in RR ( $26 \pm 7$ vs. $36 \pm 9$ breaths/min; $p=0.002)$ in all individuals.

NIV corrected $\mathrm{PaO}_{2} / \mathrm{FiO}_{2}$ in 1 patient who was discharged after 7 days, and improved $\mathrm{PaO}_{2} / \mathrm{FiO}_{2}$ in 9 pa- 


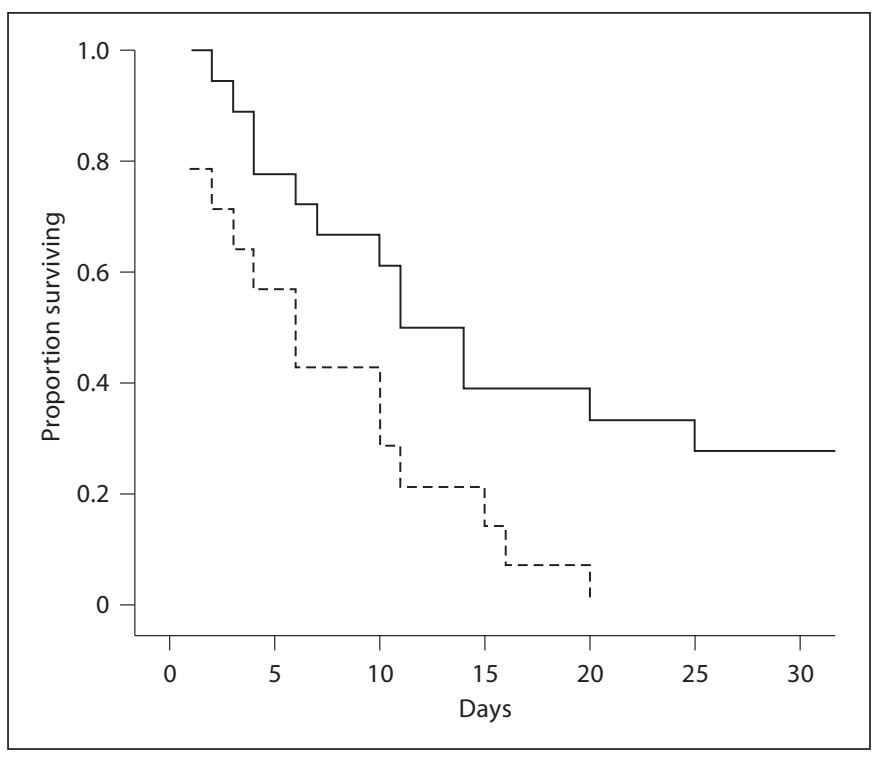

Fig. 2. Survival curve of patients included in the study. Continuous line $=$ Group B patients; dotted line $=$ group A patients. Survivors are not represented in this curve.

tients; 4 of them were discharged after $16 \pm 3.5$ days. In $5 / 19$ individuals (26.3\%), despite the observed improvement in oxygenation, NIV was withdrawn because of poor compliance (3 patients), pneumothorax (1 patient) and blood emesis (1 patient). All of them requested not to be resuscitated and died after $16 \pm 5.4$ days.

NIV failed to improve $\mathrm{PaO}_{2} / \mathrm{FiO}_{2}$ in 9 individuals: 5 underwent iMV and died after $8.8 \pm 5.8$ days and 4 died before undergoing ETI. The duration of NIV varied greatly among the 19 patients (median 9 days, with a range of $1-28$ days) for $15 \pm 2.2 \mathrm{~h} /$ day.

In the 14 patients who died during NIV (mortality rate $74 \%$ ), the causes of death were cardiac arrest in 5 patients, cardiogenic shock in 8 , and septic shock in 1 patient.

In all the 5 survivors, the causes of ARF were identified ( 2 pneumonias, 1 heart failure, 1 pneumonia associated with pleuritis, $1 \mathrm{ARF}$ after BAL).

Four of them died within 6 months from hospital discharge (range 2-6 months), 1 is still alive, and none of them were on the waiting list for lung transplantation.

Figure 1 shows the trend of $\mathrm{RR}, \mathrm{PaO}_{2} / \mathrm{FiO}_{2}, \mathrm{PaCO}_{2}$ and $\mathrm{pH}$ during MV.

Duration of MV (iMV plus NIV) positively correlated with the time of evolution of IPF $(R=0.45 ; p=0.018)$.

The survival curve of patients included in the study is shown in figure 2 (in-hospital mortality rate 85\%: 100\% for iMV, 74\% for NIV).

\section{Discussion}

This observational retrospective study describes the clinical course, MV setting and outcome of 34 end-stage IPF patients who received MV for ARF.

IPF is a progressive and usually lethal disease. The presence of refractory hypoxaemia and a marked tachypnoea characterizes the end stages of the disease and causes ARF in about $40 \%$ of patients [4]. In the first stage of ARF, alveolar hypoventilation and hypercapnia is not a common finding, probably due to respiratory muscle adaptation to the increased respiratory workload associated with lung stiffness. In the late stage, the onset of respiratory fatigue leads to $\mathrm{CO}_{2}$ retention [18]. Consistent with this observation and according to the literature [27], in our study, ARF was characterized by a rapid worsening of gas exchange with severe hypoxaemia, $\mathrm{CO}_{2}$ retention and $\mathrm{pH}$ shift towards acidosis, associated with a deterioration of the mental status. Because of the severe alterations in lung mechanics, in order to maximize alveolar recruitment, high TV values are usually applied when performing conventional MV (iMV) in IPF patients $[2-7,18]$.

This ventilatory pattern may lead to serious side effects already described for acute respiratory distress syndrome (pneumothorax and ventilator-induced lung injury) [19].

In our study, we found that iMV was able to temporarily correct $\mathrm{PaO}_{2} / \mathrm{FiO}_{2}$ in $25 \%$ of subjects, but similarly to the observations of Nava and Rubini [18], it did not modify $\mathrm{CO}_{2}$ retention (fig. 1).

In order to reduce the risk of barotrauma, protective ventilatory strategies [20] have been performed in acute respiratory distress syndrome, and, recently, in IPF patients, obtaining encouraging results [8].

In a recent retrospective study on patients with chronic interstitial lung disease (ILD) including 30 individuals with IPF, Fernandez-Perez and coworkers [21] suggest that both severity of illness and high PEEP values are associated with a decreased survival rate.

In our study, the use of PEEP values similar to those employed by Fernandez-Perez et al. [21] in the survivors' group was associated with a worst prognosis (in-hospital mortality rate $85 \%$ ), suggesting that the severity of disease should be considered crucial for the outcome.

Although NIV is considered as a first-line intervention therapy in patients with chronic obstructive pulmonary disease (COPD), and it has been successfully performed in acute cardiogenic pulmonary oedema and in childhood acute neuromuscular respiratory failure, its 
use in acute hypoxaemic respiratory failure is still under debate [22-25]. Nevertheless, NIV, compared with iMV, has fewer side effects (ventilator-acquired pneumonia and sepsis) [26].

In our study, NIV allowed the temporary correction of $\mathrm{PaO}_{2} / \mathrm{FiO}_{2}$ in 1 patient, its improvement in 9, but, as observed for iMV, failed to prevent $\mathrm{CO}_{2}$ retention. We cannot rule out that due to its large volume, the helmet may have contributed to this phenomenon. It has been assumed that breathing with a helmet is similar to breathing in a semiclosed environment, and therefore the $\mathrm{PCO}_{2}$ inside the helmet is primarily a function of the subject's $\mathrm{CO}_{2}$ production and the flow of fresh gas through the helmet. Clinical and physiological studies comparing helmet and face mask effectiveness in delivering NIV showed that the face mask was more effective than the helmet in reducing $\mathrm{CO}_{2}$ rebreathing $[27,28]$. On the other hand, it has been demonstrated that the use of the helmet to provide NIV, allowing the patients to freely communicate, drink and expectorate, improving collaboration with caregivers and clearance of the airways and decreasing the rate of complications directly related to the administration of NIV, may improve patient compliance. According to these observations, it may be possible that the use of a helmet, in the attempt to improve compliance and tolerability of NIV and avoiding the early discontinuation from MV itself, may have contributed to the outcomes observed in our study.

Importantly, a significant reduction in RR was obtained in all NIV patients.

Both ventilatory strategies failed to have a significant impact on survival rate (no survivors in the iMV group and 5 survivors in the NIV group, 4 of whom subsequently died shortly after hospital discharge).

According to the literature, in our study, cardiovascular diseases were the main cause of patients' death, possibly because of right ventricular failure due to pulmonary hypertension (all patients had electrocardiographic signs of right ventricular overload, and the 7 patients who underwent echocardiography showed severe increase in pulmonary arterial pressure) $[1,29]$. Interestingly, we observed that 5 patients had cardiac arrest as cause of death, possibly due the severe chronic hypoxaemia that characterizes IPF and its worsening during ARF. On the other hand, in our experience, we did not observe a high cardiac arrest rate using NIV in other respiratory diseases (e.g., COPD).

Although the study was not performed to compare the effectiveness of the 2 modalities of ventilation, we believe that the observation that all survivors were treated with
NIV (fig. 2) may be mainly due to the different disease severity between the 2 groups, as established by the significantly higher APACHE II score measured in patients undergoing iMV.

Despite that our study was retrospective and limited to 1 medical centre, to the best of our knowledge, no prospective multi-centre studies have been performed in this field and, importantly, to date, our report is the study which analyses the largest sample size of patients undergoing MV because of ARF during IPF.

In IPF patients, NIV has been analysed in only a few retrospective studies evaluating a small number of patients; 5 in the study by Blivet et al. [2], 11 in the study by Fumeaux et al. [4], 7 in the study by Saydain et al. [5], and 1 in the report by Nava and Rubini [18]. Unfortunately, no data on IPF patients treated with NIV are available in the study of Fernandez-Perez et al. [21].

These authors found that NIV avoided ETI in $1 / 5$ (20\%), 0/11 (0\%), 1/7 (14\%) and 0/1 (0\%) patients, respectively. In our study, NIV prevented ETI in 5/19 individuals (26\%).

Furthermore, since in the only survivor still alive, ARF had arisen as a complication during diagnostic procedures (BAL) and since the patient was discharged after 1 week, we cannot exclude that the clinical conditions may have improved despite therapies.

Still, we cannot rule out that an early intervention with NIV, in patients with a clinical condition not yet as severe as in the iMV group, may have been crucial in the outcome observed.

\section{Conclusion}

The institution of MV in patients with ILD may raise philosophical questions based on the expected prognosis [30]. A difference in outcome of ILD patients undergoing MV may be due to clinical and radiologic features and a pathologic 'pattern' [31], timing and type of therapeutic intervention, patients' severity illness score, and MV approach (high vs. low TV and iMV vs. NIV).

Despite its substantial inability to modify the estimated life expectancy of IPF patients, our data, although lacking a validated measurement scale, suggest that NIV, significantly decreasing the RR, may be considered a capital palliative option that, together with other medical supports, may help to reduce patient discomfort, avoiding more aggressive approaches. Furthermore, in addition to this, to the best of our knowledge, this is the first study on IPF patients with ARF performed in a RIICU. 
This setting has recently been demonstrated to be a costeffective alternative to ICUs in the treatment of COPD patients [32]. We cannot rule out that a subset of IPF patients could be less costly treated in RIICUs.
Prospective multi-centre studies should be performed to investigate the role of MV, especially NIV, as a compassionate approach and/or as early intervention in IPF patients with ARF.

\section{References}

1 Panos RJ, Mortenson RL, Niccoli SA, King TE Jr: Clinical deterioration in patients with idiopathic pulmonary fibrosis: causes and assessment. Am J Med 1990;88:396-404.

2 2 Blivet S, Philit F, Sab JM, Langevin B, Paret M, Guerin C, Robert D: Outcome of patients with idiopathic pulmonary fibrosis admitted to the ICU for respiratory failure. Chest 2001;120:209-212.

- 3 Stern JB, Mal H, Groussard O, Brugière O, Marceau A, Jebrak G, Fournier M: Prognosis of patients with advanced idiopathic pulmonary fibrosis requiring mechanical ventilation for acute respiratory failure. Chest 2001; 120:213-219.

-4 Fumeaux T, Rothmeier C, Jolliet P: Outcome of mechanical ventilation for acute respiratory failure in patients with pulmonary fibrosis. Intensive Care Med 2001;27:18681874.

5 Saydain G, Islam A, Afessa B, Ryu JH, Scott JP, Peters SG: Outcome of patients with idiopathic pulmonary fibrosis admitted to the intensive care unit. Am J Respir Crit Care Med 2002;166:839-842.

-6 Al-Hameed FM, Sharma S: Outcome of patients admitted to the intensive care unit for acute exacerbation of idiopathic pulmonary fibrosis. Can Respir J 2004;11:117-122.

7 Molina-Molina M, Badia JR, Marin-Arguedas A, Xaubet A, Santos MJ, Nicolas JM, Ferrer M, Torres A: Outcomes and clinical characteristics of patients with pulmonary fibrosis and respiratory failure admitted to an intensive care unit. A study of 20 cases. Med Clin (Barc) 2003;121:63-67.

-8 Suh GY, Kang EH, Chung MP, Lee KS, Han J, Kitaichi M, Kwon OJ: Early intervention can improve clinical outcome of acute interstitial pneumonia. Chest 2006;129:753-761.

-9 Estenssoro E, Gonzàles F, Laffaire E, Canales H, Sàenz G, Reina R, Dubin A: Shock on admission day is the best predictor of prolonged mechanical ventilation in the ICU. Chest 2005; 127:598-603.

10 American Thoracic Society (ATS) and European Respiratory Society (ERS): Idiopathic pulmonary fibrosis: diagnosis and treatment. International consensus statement. Am J Respir Crit Care Med 2000;161:646664.

11 Bone RC, Balk RA, Cerra FB, Dellinger RP, Fein AM, Knaus WA, Schein RM, Sibbad WJ: Definitions for sepsis and organ failure and guidelines for the use of innovative therapies in sepsis. The ACCP/SCCM Consensus Con- ference Committee. American College of Chest Physicians/Society of Critical Care Medicine. Chest 1992;101:1644-1655.

12 Teasdale G, Jennett B: Assessment of coma and impaired consciousness. A practical scale. Lancet 1974;ii:81-84.

13 International Consensus Conference in Intensive Care Medicine: non-invasive positive-pressure ventilation in acute respiratory failure. Am J Respir Crit Care Med 2001;163: 283-291.

14 Knaus WA, Draper EA, Wagner DP, Zimmerman JE: APACHE II: a severity of disease classification system. Crit Care Med 1985;13: 818-829.

15 Meduri GU, Conoscenti CC, Menashe P, Nair S: Noninvasive face mask ventilation in patients with acute respiratory failure. Chest 1989;95:865-870.

16 Suter PM, Fairley B, Isemberg MD: Optimum end-expiratory airway pressure in patients with acute pulmonary failure. $\mathrm{N} \mathrm{Engl}$ J Med 1975;292:284-289.

17 Sassoon CS, Giron AE, Ely EA, Light RW: Inspiratory work of breathing on flow-by and demand-flow continuous positive airway pressure. Crit Care Med 1989;17:1108-1114.

18 Nava S, Rubini F: Lung and chest wall mechanics in ventilated patients with end stage idiopathic pulmonary fibrosis. Thorax 1999; 54:390-395

19 Tremblay L, Valenza F, Ribeiro SP, Li J, Slutsky AS: Injurious ventilatory strategies increase cytokines and c-fos m-RNA expression in an isolated rat lung model. J Clin Invest 1997;99:944-952.

20 Ventilation with lower tidal volumes as compared with traditional tidal volumes for acute lung injury and the acute respiratory distress syndrome. The Acute Respiratory Distress Syndrome Network. N Engl J Med 2000;342:1301-1308.

21 Fernandez-Perez ER, Ylmaz M, Jenad H, Daniels CE, Ryu JH, Hubmayr RD, Gajic O: Ventilator settings and outcome of respiratory failure in chronic interstitial lung disease. Chest 2008;133:1113-1119.

22 Peter JV, Moran JL, Phillips-Hughes J, Warn D: Non-invasive ventilation in acute respiratory failure - a meta-analysis update. Crit Care Med 2002;30:555-562.

23 Valipur A, Cozzarini W, Burghuber OC: Non-invasive pressure support ventilation in patients with respiratory failure due to severe acute cardiogenic pulmonary edema. Respiration 2004;71:144-151.
24 Piastra M, Antonelli M, Caresta E, Chiaretti A, Polidori G, Conti G: Noninvasive ventilation in childhood acute neuromuscular respiratory failure: a pilot study. Respiration 2006;73:791-798.

25 Antonelli M, Pennisi MA, Montini L: Clinical review: non-invasive ventilation in the clinical setting - experience from the past 10 years. Crit Care 2005;9:98-103.

26 Antonelli M, Conti G, Rocco M, Bufi M, De Blasi RA, Vivino G, Gasparetto A, Meduri GU: A comparison of non-invasive positivepressure ventilation and conventional mechanical ventilation in patients with acute respiratory failure. N Engl J Med 1998;339: 429-435.

27 Chiumello D, Pelosi P, Carlesso E, Severgnini P, Aspesi M, Gamberoni C, Antonelli M, Conti G, Chiaranda M, Gattinoni L: Noninvasive positive pressure ventilation delivered by helmet vs standard face mask. Intensive Care Med 2003;29:1671-1679.

-28 Navalesi P, Costa R, Ceriana P, Carlucci A, Prinianakis G, Antonelli M, Conti G, Nava S: Non-invasive ventilation in chronic obstructive pulmonary disease patients: helmet versus facial mask. Intensive Care Med 2007;33:74-81.

29 Nathan SD, Shlobin OA, Ahmad S, Koch J, Barnett SD, Ad N, Burton N, Leslie K: Serial development of pulmonary hypertension in patients with idiopathic pulmonary fibrosis. Respiration 2008;76:288-294.

30 Baydur A: Mechanical ventilation in interstitial lung disease: which patients are likely to benefit? Chest 2008;133:1062-1063.

- 31 Travis WD, Hunninghake G, King TE Jr, Lynch DA, Colby TV, Galvin JR, Brown KK, Chung MP, Cordier JF, du Bois RM, Flaherty KR, Franks TJ, Hansell DM, Hartman TE, Kazerooni EA, Kim DS, Kitaichi M, Koyama T, Martinez FJ, Nagai S, Midthun DE, Müller NL, Nicholson AG, Raghu G, Selman M, Wells A: Idiopathic nonspecific interstitial pneumonia. Report of an American Thoracic Society project. Am J Crit Care Med 2008; 177:1338-1347.

32 Bertolini G, Confalonieri M, Rossi C, Rossi G, Simini B, Gorini M, Corrado A; GiViTI (Gruppo italiano per la Valutazione degli interventi in Terapia Intensiva) Group; Aipo (Associazione Italiana Pneumologi Ospedalieri) Group: Costs of the COPD. Differences between intensive care unit and respiratory intermediate care unit. Respir Med 2005;99: 894-900. 